\title{
RESENHA DO LIVRO “GRUPO TEATRO DO MOVIMENTO: UM GESTO EXPRESSIVO DE KLAUSS E ANGEL VIANNA NA DANÇA BRASILEIRA"
}

\author{
Marina Magalhães ${ }^{\mathrm{i}}$ \\ Joana Ribeiro ${ }^{\text {ii }}$
}

\begin{abstract}
Resumo: O livro "Grupo Teatro do Movimento: Um gesto expressivo de Klauss e Angel Vianna na dança brasileira" aborda a trajetória do Grupo Teatro do Movimento (GTM), companhia de dança fundada por Klauss e Angel Vianna em 1976, no Rio de Janeiro. Considerada uma das precursoras da dança contemporânea carioca, influenciou toda uma geração de artistas e coreógrafos. Contextualiza o GTM perante as políticas culturais da época, que possibilitaram sua gênese e circulação. Retrata e analisa obras e parcerias com artistas como: Lourdes Bastos, Lola Brikman, José Possi Neto e Oscar Araiz. Apresenta a pesquisa Significado e função de uma linguagem gestual e sua conotação no campo da dança (1977-1978) coordenada pelos Vianna, e suas imbricações no GTM. Revela, por fim, à dança brasileira, procedimentos técnicos e criativos sob os auspícios de Angel Vianna.
\end{abstract}

Palavras-chaves: Grupo Teatro do Movimento; Klauss Vianna; Angel Vianna; Dança Brasileira.

\section{RESEÑA DEL LIBRO “GRUPO TEATRO DO MOVIMENTO: UM GESTO EXPRESSIVO DE KLAUSS E ANGEL VIANNA NA DANÇA BRASILEIRA”}

Resumen: El libro "Grupo Teatro do Movimento: Um gesto expressivo de Klauss e Angel Vianna na dança brasileira" aborda la trayectoria del Grupo Teatro do Movimento (GTM), compañía de danza fundada por Klauss y Angel Vianna en 1976, en Rio de Janeiro. Considerada una de las precursoras de la danza contemporánea carioca, influyó toda una generación de artistas y coreógrafos. Contextualiza el GTM frente las políticas culturales de la época, que posibilitaron su génesis y circulación. Retrata y analiza obras y asociaciones con artistas como: Lourdes Bastos, Lola Brikman, José Possi Neto y Oscar Araiz. Presenta la investigación Significado e função de uma linguagem gestual y su connotación en el campo de la danza (1977-1978) coordenada por Vianna, y sus superposiciones en el GTM. Revela, finalmente, a la danza brasileña, procedimientos técnicos y creativos bajo los auspicios de Angel Vianna.

Palabras clave: Grupo de Teatro del Movimiento; Klauss Vianna; Angel Vianna; Danza brasileña.

O Grupo Teatro do Movimento foi o nosso primeiro trabalho com companhia de dança no Rio de Janeiro, com pessoas incríveis! E foi graças ao Pacote Cultural que o Teatro do Movimento pôde viajar. Na ocasião, o diretor Paulo Afonso Grisolli perguntou: - Angel, você tem companhia de dança? Já estava com algumas pessoas na cabeça, mas se falasse que não tinha não saberia o que ele queria fazer... (VIANNA, Angel. Grupo Teatro do Movimento: um gesto expressivo de Klauss e Angel Vianna na dança brasileira. Rio de Janeiro: Gramma, 2019 - contracapa). 


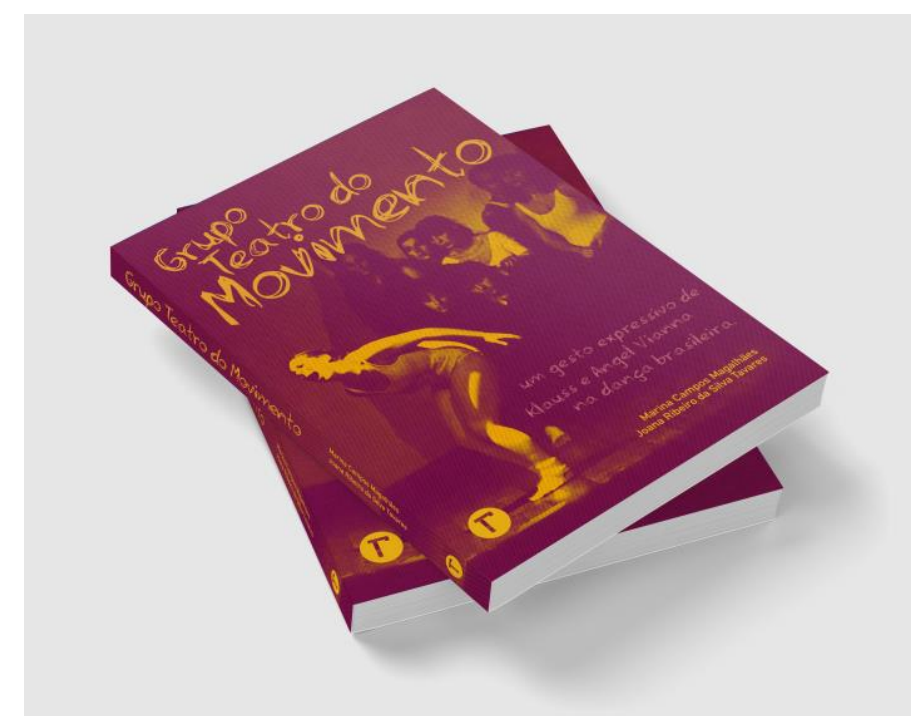

Fig 1 - Capa de Paulo Ferreira. Foto: Acervo Angel Vianna.

\section{Introdução}

Com apresentação de Giselle Ruiz, prefácio de Cássia Navas e texto de contracapa da mestra Angel Vianna, o livro Grupo Teatro do Movimento: um gesto expressivo de Klauss e Angel Vianna na dança brasileira aborda, de forma inédita, a trajetória do Grupo Teatro do Movimento (GTM): companhia de dança fundada pelo casal de bailarinos Klauss e Angel Vianna em 1976, no Rio de Janeiro. Considerada uma das precursoras da dança contemporânea carioca, a companhia influenciou toda uma geração de artistas e coreógrafos.

O livro é resultado de pesquisa desenvolvida junto ao Mestrado Acadêmico do Programa de Pós-graduação em Artes Cênicas da Unirio, com financiamento da CAPES, por Marina Campos Magalhães, sob orientação de Joana Ribeiro da Silva Tavares, e defendida em 2017. A publicação em formato de livro impresso e $e$-book - pela editora Gramma, do Rio de Janeiro - foi realizada por meio de campanha de financiamento coletivo no ano de 2019.

Grupo Teatro do Movimento: um gesto expressivo de Klauss e Angel Vianna na dança brasileira contextualiza o GTM perante as políticas culturais da época que possibilitaram sua gênese e circulação. Mapeia e analisa obras e parcerias com artistas como Oscar Araiz (1940-), Lourdes Bastos (1927-), Lola Brikman e José Possi Neto (1947-). Apresenta a pesquisa Significado e função de uma linguagem gestual e sua conotação no campo da dança (1977-1978), coordenada pelos Vianna e suas imbricações no GTM. Revela, 


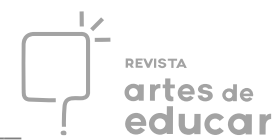

por fim, à dança brasileira procedimentos técnicos e criativos sob os auspícios de Angel Vianna.

O Grupo Teatro do Movimento foi idealizado pelo casal Klauss e Angel Vianna, sob a direção geral de Angel Vianna, recebendo colaboração de outros coreógrafos. O GTM pode ser considerado uma das primeiras companhias de pesquisa em dança moderna/contemporânea com subvenção estatal no Rio de Janeiro, segundo Tavares et al. (2010a, 2010b, 2013), e destaca-se tanto pelo ineditismo de seus processos de criação, quanto pela abordagem ética e estética de seu trabalho. Com o GTM, os Vianna inauguraram no Rio de Janeiro um pensamento sobre a dança em que qualquer pessoa poderia dançar, qualquer movimento poderia ser dança, qualquer espaço físico poderia ser utilizado como espaço cênico, em uma estreita relação com o Manifesto de Merce Cunningham ${ }^{1}$.

Criado em 1976, o grupo desenvolveu, ao longo de três anos, 11 obras coreográficas: Domínio Público (1976), de Oscar Araiz; Corações Futuristas (1976), Luiza Porto (1976) e Eterna (1977), de Lourdes Bastos; Pulsações (1976), de Lola Brikman; Improviso (1976) de Graciela Figueroa; Animus (1977) e O Filho do Rei (1978), de Michel Robin; Mal Aria Ba! (1978), de José Possi Neto; Passagem (1978), de Mariana Vidal e Construção (1978), de Angel Vianna. Desde o primeiro trabalho, já é possível apontar características de uma incipiente dança contemporânea carioca, como a pesquisa de movimento e a busca por uma nova linguagem artística.

Essas obras foram apresentadas nas capitais dos estados do Rio de Janeiro e de São Paulo, além de diversas cidades do interior fluminense, participando de projetos que surgiram na década de 1970, como iniciativas no campo das políticas culturais, como o Projeto Pacote Cultural, o Projeto Dança, o Palco sobre Rodas e o Primeiro Ciclo de Dança Contemporânea. Outras parcerias também foram de grande importância para a manutenção e subsistência do grupo, como a estabelecida com o Museu de Arte Moderna (MAM) do Rio de Janeiro e com os Encontros de Dança, organizados por Rainer Vianna (1958-1995)².

Afora as obras coreográficas, o intuito de elaborar uma nova linguagem artística instigou o Grupo Teatro do Movimento à realização do projeto-pesquisa Significado e função de uma linguagem gestual e sua conotação no campo da dança (1977-1978). Com esse projeto, pela primeira vez no Rio de Janeiro, um grupo de vanguarda recebeu uma subvenção estatal para implementar uma pesquisa teórico-prática na área da dança. Significado e função pretendia fazer uma análise das escolas e profissionais de dança e movimento, com enfoque 


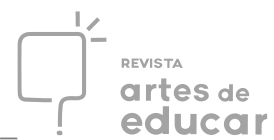

sobre a lúdica infantil e o gestual cotidiano, a fim de fomentar a investigação sobre a dança brasileira - e retomar uma pesquisa iniciada pelo casal Vianna na década de 1950, em Belo Horizonte.

A escolha da temática desse livro teve como principal motivação o pioneirismo do Grupo Teatro do Movimento, bem como de seus idealizadores: Klauss e Angel Vianna, que começaram a dançar em Belo Horizonte, no Ballet de Minas Gerais, com o professor Carlos Leite (1914-1995), no final da década de 1940. Juntos fundaram, na década seguinte, sua primeira escola e companhia de dança na capital mineira, respectivamente, a Escola e o Ballet Klauss Vianna, marco inicial da pesquisa do casal sobre a dança brasileira, que já apresentava aspectos multidisciplinares, tanto no que se refere à criação quanto à formação artística. $\mathrm{Na}$ década de 1960, mudaram-se para o Rio de Janeiro; foi quando se aproximaram também do teatro por conta do trabalho de preparação corporal para atores. O Grupo Teatro do Movimento foi criado na década de 1970 e dedicou-se a uma pesquisa de linguagem gestual em dança, intitulada como expressão corporal, como meio de desenvolver a consciência corporal e a expressão do sujeito, para chegar à construção de uma dança brasileira.

Os Vianna influenciaram toda uma geração de artistas, coreógrafos e pesquisadores no Brasil, com suas investigações sobre o gesto e seus conhecimentos sobre o corpo e o movimento. É visível e necessário destacar o quanto a produção bibliográfica sobre a obra do casal vem se avolumando nos últimos anos. Entretanto, especificamente no que concerne ao Grupo Teatro do Movimento, as referências bibliográficas são escassas. Em Freire (2005), Ribeiro (2018) e Ramos (2007), encontra-se um primeiro levantamento sobre a obra do GTM. Já o Grupo de Pesquisa Artes do Movimento abordou o tema em três ${ }^{3}$ artigos, que consistem em atualizações da Homenagem ao Grupo Teatro do Movimento $^{4}$ lançada no II Engrupedança $^{5}$, em 2009. Cerbino e Brum (2013), no livro Movimento da dança carioca companhias e Grupos de 1936 a 2013, traçam um histórico resumido do grupo. Finalmente, as outras três publicações que citam o Grupo Teatro do Movimento são: Aquino (2005) e Ruiz (2013a, 2013b).

O livro Grupo Teatro do Movimento: um gesto expressivo de Klauss e Angel Vianna na dança brasileira busca reconstruir e analisar a trajetória de um grupo que participou da transformação da dança cênica carioca, em pleno regime de ditadura militar. Sem dúvida, a reconstrução histórica tem uma importante função na preservação da memória e no desenvolvimento das sociedades. Narrar uma história parte da necessidade de comunicar, mas 


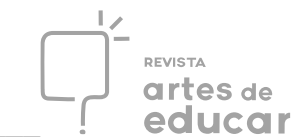

também da intenção de que esse conhecimento permaneça vivo ao longo do tempo. Além disso, a historiografia da dança deve considerar ainda que a dança, como processo histórico, ocorre no corpo e na cena por ela estabelecida. Ou seja, a própria dança é o melhor meio para conhecê-la. Como salienta Ruiz (2019, p. 14), na apresentação do livro, “ao ouvir tanto a fala dos bailarinos quanto a dos criadores dessa linguagem, o leitor percebe que os 'Vianna' certamente tinham uma visão à frente do seu tempo e que, como nos lembra o próprio texto, 'Dançar é poesia'".

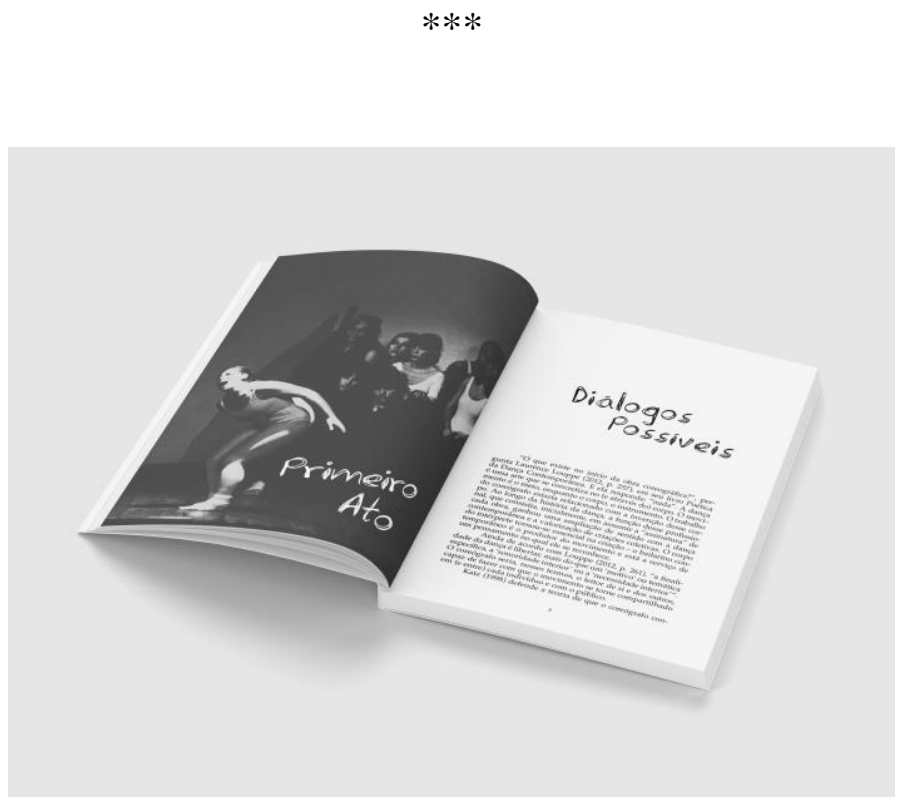

Fig 2 - Miolo. Diagramação de Paulo Ferreira.

\section{Sobre o sumário}

A trajetória do Grupo Teatro do Movimento é apresentada neste livro como um processo artístico, como se o leitor estivesse à frente de um espetáculo de dança. São 200 páginas divididas entre: apresentação, prefácio, introdução, prólogo, três "atos-capítulos", dois "intervalos", considerações finais e anexos. Cada "ato-capítulo" se refere a um aspecto dessa criação, contribuindo com a reconstrução desse percurso/narrativa. Ao fim dos primeiros capítulos, encontram-se "intervalos", nos quais novos elementos são insertos, enriquecendo a leitura e as impressões sobre o trabalho.

Tanto Ruiz quanto Navas (2019), destacam esta originalidade formal da obra que, nas palavras de Ruiz (2019, p. 14), "aguça a curiosidade e a imaginação do leitor, que 


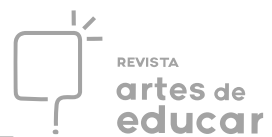

imediatamente se vê transportado para o mundo da dança". Essa escolha parece contribuir para que o texto, além de informativo, seja também uma experiência compartilhada. Além disso, Ruiz e Navas (2019) salientam o aspecto inovador da metodologia desenvolvida que mescla o minucioso rigor histórico a ousadas reflexões.

No Prólogo, desenha-se um breve panorama cultural do Brasil nas décadas de 1960 e 1970, que configura o contexto no qual surgiu o Grupo Teatro do Movimento. Contém uma síntese das políticas culturais que, nesse contexto histórico, beneficiaram o GTM. A seção mapeia as origens do Grupo Teatro do Movimento, em que se destacam a Geração Complemento, a Escola e o Ballet Klauss Vianna, além do Grupo Brincadeiras - antecessor do GTM -, e do Centro de Pesquisa Corporal Arte e Educação ${ }^{6}$.

Primeiro Ato - Diálogos Possíveis - está dividido em dois subcapítulos que analisam as obras dos coreógrafos convidados para atuar no GTM e os espetáculos resultantes. No primeiro - As Obras Coreográficas -, são apresentados os coreógrafos convidados e os trabalhos desenvolvidos por eles: Oscar Araiz (Domínio Público), Lourdes Bastos (Luiza Porto; Corações Futuristas e Eterna), Lola Brikman (Pulsações) e José Possi Neto (Mal Aria $B a !)$. Além dos coreógrafos convidados, os próprios bailarinos do Grupo Teatro do Movimento criaram solos que integraram o repertório do grupo, contribuindo na construção de uma linguagem própria de dança. Destacam-se o solo de Graciela Figueroa, Improviso (1976); os dois trabalhos de Michel Robin, Animus (1977) e O Filho do Rei (1978); e o solo de Mariana Vidal, Passagem (1978) - que são vistos em conjunto. O segundo subcapítulo Os Espetáculos - enfoca as três montagens: Movimento e Forma, Forma e Espaço e Domínio Público, criadas com a orquestração das obras analisadas anteriormente.

Até a década de 1970, o método de trabalho mais comumente aplicado nas companhias de dança brasileiras privilegiava o coreógrafo como "o criador" nos processos de composição coreográfica. O deslocamento desse foco para o "bailarino pensante e atuante", como denominava Angel Vianna, ganhou espaço nas décadas seguintes, ampliando o campo de atuação do intérprete/bailarino para a criação e a pesquisa em dança.

Segundo Ato - Por uma nova linguagem cênica - aborda o projeto-pesquisa Significado e função de uma linguagem gestual e sua conotação no campo da dança, desenvolvido durante o biênio de 1977 e 1978, com o objetivo de pesquisar a dança brasileira. O capítulo divide-se em três subcapítulos. O primeiro - Preparando o Terreno - investiga a etapa preparatória do projeto, em que foram oferecidos aos bailarinos cursos com o objetivo 


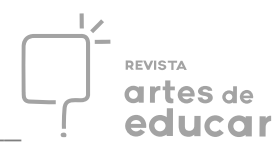

de prepará-los para as fases seguintes. O segundo - Pesquisa de Campo - dedica-se às pesquisas in loco feitas pelos bailarinos-pesquisadores: a primeira, referente às escolas de dança ou movimento, visava compreender a formação dos bailarinos e professores de dança, enquanto a segunda, realizada em locais diversos, focava os jogos e as brincadeiras infantis e sua relação com a gestualidade e a cultura brasileira. O terceiro subcapítulo - Os Espetáculos - analisa o que foi denominado como "resultado" artístico do projeto, abrangendo as montagens: Ideótica (1978), Painel (1978) e Esboço (1978).

O livro analisa esse projeto realçando as diferenças entre movimento e gesto, segundo o entendimento dos Vianna, e a emergência da dança brasileira à qual se dedicavam. A “formação experimental" realizada para os bailarinos, com o objetivo de prepará-los a posterior pesquisa de campo, foi realizada por renomados professores convidados que ministraram os cursos de anatomia (Gesto-somático), música (Gesto-som), Danças Folclóricas Brasileiras (Gesto e Cultura) e Teoria da Percepção (Gesto e percepção). De acordo com Ruiz (2019, p. 14), ao longo do texto, ao detalhar esses cursos, há informações preciosas sobre como o modo de investir em formação é capaz de trazer uma valiosa contribuição para a criação de uma linguagem cênica de grupo.

Esse projeto pretendeu ainda um mapeamento sobre a formação e a atuação do profissional da dança, pois levantou questões consideráveis em um momento de desenvolvimento desse setor artístico, tanto no âmbito profissional, quanto em sua relação com as políticas culturais. A pesquisa de campo sobre a lúdica infantil apresenta uma investigação sobre jogos corporais e brincadeiras, que são uma constante no trabalho corporal dos Vianna. Além disso, Angel Vianna defende o fato de que a pesquisa de movimento em dança tem uma relação direta com o aprendizado da criança, que se dá de forma fundamentalmente experiencial.

Terceiro Ato - Dançar é poesia - divide-se em três subcapítulos que examinam: a dança brasileira realizada pelo Grupo Teatro do Movimento; os procedimentos técnicos utilizados; e a última obra do GTM, Construção. O primeiro - A Dança Brasileira do GTM: a Dança de Klauss e Angel Vianna - discute o conceito de "dança brasileira" por meio da análise das obras coreográficas dos Vianna, em contraponto ao trabalho realizado pelo GTM. O subcapítulo - Procedimentos Técnicos: "todo mundo pode dançar" - detém-se no trabalho corporal realizado nas aulas de expressão corporal, utilizado como processo formativo dos bailarinos. Finalmente, o subcapítulo - Construção (1978) - Angel Vianna: a "arte da 


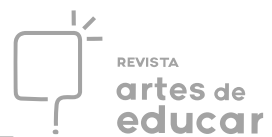

existência" - apresenta a última obra do GTM, dirigida por Angel Vianna.

A construção à qual se refere o título da obra, na perspectiva de Angel Vianna, dava-se de forma desconstruída e poderia ser em relação a tudo: ao corpo, à dança, à vida, ao ser humano, ao espaço e à música. Essa obra pode ser considerada uma metáfora do trabalho corporal desenvolvido pela família Vianna, na época, denominado expressão corporal, na qual a brincadeira e o jogo são aliados do processo de criação de um novo corpo, uma nova dança, uma nova poética corporal.

A expressão corporal, como procedimento técnico utilizado pelo Grupo Teatro do Movimento, não se reduzia a propostas de passos, formas, sequências ou posturas a priori ao contrário: objetivava, por meio do autoconhecimento e da investigação corporal, chegar aos movimentos, sequências, formas ou posturas de cada um. Para Vianna (2005, p. 73), $a$ técnica de dança tem apenas uma finalidade: preparar o corpo para responder à exigência do espírito artístico.

O professor, para os Vianna, deveria guiar um processo de ensino-aprendizagem. Seus objetivos ultrapassam aqueles de um instrutor, ou mestre de tarefas, voltados para a transmissão de conhecimento. O professor, neste lugar, mostra um caminho, para que cada aluno possa adquirir conhecimento por si mesmo, encorajando-o nesse processo. Katz (2009) aproxima essa maneira de ensinar à maiêutica de Sócrates, o "conhece-te a ti mesmo", que tem como significado "dar à luz" (referindo-se ao ato da parteira): "parir" o conhecimento, a "verdade", latente em todo ser humano.

Os Intervalos (no final do primeiro e do segundo capítulos) e as Considerações Finais - Coda - aportam reflexões sobre a trajetória do Grupo Teatro do Movimento. O texto formado por esses "atos-capítulos" é ainda amparado por fotografias cedidas pelo Acervo Angel Vianna - mapas, tabelas e Anexos -, que contém uma cronologia das apresentações do grupo, bem como as fichas técnicas das obras e espetáculos.

$$
* * *
$$

\section{Um convite à leitura}

Grupo Teatro do Movimento: um gesto expressivo de Klauss e Angel Vianna na dança brasileira levanta temas inéditos sobre a historiografia da dança no Brasil, ampliando o 


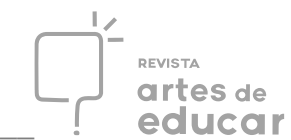

estado da arte, especialmente no que se relaciona à dança da década de 1970 e à gênese da dança contemporânea carioca. Nesse sentido, o livro apresenta um breve mapeamento histórico da dança moderna e contemporânea no Brasil, com enfoque no período de atuação do GTM no Rio de Janeiro.

Diferentemente da maior parte das publicações sobre os Vianna, nas quais o cerne está nas ações pedagógicas do casal, este livro apresenta as questões artísticas de Angel e Klauss Vianna e suas investigações sobre a dança brasileira. No prefácio do livro, a pesquisadora Navas (2019) destaca o prólogo e o terceiro ato que, articulados, elucidam sobre vetores de um mesmo contexto da arte no Brasil: a ditadura militar e os tempos da contracultura. Essa autora (idem, p. 16) finaliza seu texto afirmando que conhecer o grupo de Klauss e Angel Vianna deve nutrir novas gerações de artistas por memórias recolocadas na cena atual. Este livro é território desta experiência e, ao mesmo tempo, espessa linha de passe para uma atualização do muito já feito na dança do Brasil.

O livro apresenta as ações artísticas dos Vianna como uma abertura para a percepção da dança no país, em sua acepção mais moderna e contemporânea. Ademais, analisa a investigação dos Vianna sobre o corpo cotidiano e suas relações dramatúrgicas, o que, por sua vez, inaugura uma nova construção estética que tem o corpo e o sujeito como protagonistas.

É importante realçar como as políticas públicas foram fundamentais na gênese e continuidade do Grupo Teatro do Movimento. Uma das primeiras companhias de dança contemporânea a receber subvenção estatal, o GTM teve sua criação atrelada à participação no Pacote Cultural de 1976. Ao longo de sua trajetória, a permanência do GTM também se deve a outras iniciativas públicas e privadas, e seu término coincide, em 1978, com o fim do financiamento do projeto Significado e função de uma linguagem gestual pela Funarte.

O Grupo Teatro do Movimento desfez-se no final da década de 1970. Sua influência atingiu toda uma geração de artistas, coreógrafos e pesquisadores. Destaca-se o Grupo Coringa (1977-1985), dirigido por Graciela Figueroa, que havia sido bailarina do GTM, o qual, por sua vez, gerou novos grupos, como a Intrépida Trupe, a Companhia de Dança Deborah Colker, a Cia. Aérea de Dança e a Grande Cia. de Mystérios e Novidades.

Apesar de Angel Vianna ter tentado manter o grupo com recursos próprios após o fim da subvenção da Funarte, o encerramento de suas atividades tornou-se inevitável. Não foram encontrados indícios de atividades do GTM após 1979, optando-se por considerar seu término no ano de 1978. Ao longo de suas trajetórias didático-artísticas, Klauss e Angel Vianna 


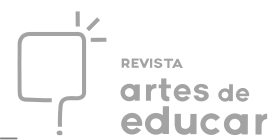

priorizaram o sujeito, a descoberta do movimento, das singularidades, da dança de cada um. A leitura deste livro é um convite para conhecermos a trajetória do Grupo Teatro do Movimento, revelando um agrupamento regido por uma maiêutica socrática, tal qual um gesto parteiro, que se expande em gesto expressivo na dança brasileira.

\section{REFERÊNCIAS}

AQUINO, Dulce. Anos 70, O Brasil e a Dança. In: RISÉRIO, Antônio; FREIRE, Maria C. M.; KEHL, Maria Rita et al. (orgs.). Anos 70: Trajetórias. São Paulo: Iluminuras, 2005.

BANNES, Sally. Terpsichore in Sneakers: Post-Modern Dance. Wesleyan University Press, 1987.

CERBINO, Beatriz; BRUM, Leonel. Movimentos da dança carioca - companhias e grupos de 1936 a 2013. Rio de Janeiro: Jauá Editora, 2013.

FREIRE, Ana Vitória. Angel Vianna - uma biografia da dança contemporânea. Rio de Janeiro: Dublin, 2005.

KATZ, Helena. "Método e técnica: faces complementares do aprendizado em dança". In: SALDANHA, Suzana (org.). Angel Vianna. Sistema, método ou técnica? Rio de Janeiro: Funarte, 2009.

MAGALHÃES, Marina; NAVAS, Cássia. Rio de Janeiro: Gramma, 2019, p. 15-16.

NAVAS, Cássia. Prefácio - Em livro, reapresentar a experiência da dança. In: MAGALHÃES, Marina; NAVAS, Cássia. Grupo Teatro do Movimento: um gesto expressivo de Klauss e Angel Vianna na dança brasileira Rio de Janeiro: Gramma, 2019.

RAMOS, Enamar. Angel Vianna: a pedagoga do corpo. São Paulo: Summus, 2007.

RIBEIRO, Juliana Costa. Angel Vianna através da história: a trajetória da dança da vida. Curitiba: Editora Appris, 2018.

RUIZ, Giselle. Apresentação. Grupo Teatro do Movimento: um gesto expressivo de Klauss e Angel Vianna na dança brasileira. In: MAGALHÃES, Marina; NAVAS, Cássia. Grupo Teatro do Movimento: um gesto expressivo de Klauss e Angel Vianna na dança brasileira Rio de Janeiro: Gramma, 2019, p. 13-14.

. Arte/Cultura em momento de trânsito: O MAM/RJ na década de 1970. Rio de Janeiro: Mauad X, Faperj, 2013a.

Graciela e Grupo Coringa: a dança contemporânea carioca dos anos 1970/80.

Rio de Janeiro: Mauad X, $2013 b$. 
TAVARES, Joana Ribeiro da Silva, et al. Homenagem ao Grupo Teatro do Movimento 1975-1980. II ENGRUPEDANÇA: Diálogos e Dinâmicas. Rio de Janeiro, p. XVII-XXVI, 2010a.

Grupo Teatro do Movimento: uma proposta de pesquisa em dança. O Percevejo

Online. Rio de Janeiro, v. 2, n. 2, p. 1-13, 2010 b.

Grupo Teatro do Movimento (1975-1980). In: TAVARES, Joana Ribeiro da Silva, KEISERMAN, Nara (orgs.). O corpo cênico: entre a dança e o teatro. São Paulo: Annablume; Rio de Janeiro: Unirio; Capes, 2013. p. 89-98.

VIANNA, Klauss. A dança. São Paulo: Summus, 2005.

i Marina Campos Magalhães - Doutoranda em Artes pela Universidade de Lisboa (com bolsa da Fundação para a Ciência e a Tecnologia - FCT), Mestre em Artes Cênicas pela Unirio e pós-graduada em Preparação Corporal pela Faculdade Angel Vianna. Foi professora da Escola Superior de Dança do Instituto Politécnico de Lisboa e da Escola e Faculdade Angel Vianna. Email: marinacmagalhaes@ gmail.com

ii Joana Ribeiro da Silva Tavares - Professora da Escola de Teatro da Unirio. Pesquisadora dos Programas de Pós-Graduação em Artes Cênicas e Pós-Graduação em Ensino de Artes Cênicas da UNIRIO. Pós-doutora pela Universidade Paris-8. Autora dos livros: Klauss Vianna: do coreógrafo ao diretor e O corpo cênico entre a dança e o teatro (Annablume, 2010 e 2013). Coordenadora do Laboratório Artes do Movimento no Centro de Letras e Artes da Unirio. Email: jr098343@gmail.com

1 O manifesto de Merce Cunningham afirma que: "todo movimento pode ser material de dança; 2) todo procedimento pode ser um método de composição válido; 3) qualquer parte ou partes do corpo podem ser usadas (sujeito apenas a limitações da própria natureza); 4) música, figurino, cenário, iluminação e dança possuem lógica e identidade próprias separadas; 5) qualquer bailarino da companhia pode ser solista; 6) qualquer espaço pode ser usado para dança; 7) a dança pode falar e ser sobre qualquer coisa, mas é primeiro e fundamentalmente sobre o corpo humano e seus movimentos, a começar pelo andar.

Do original: "1) any movement can be material for a dance; 2) any procedure can be a valid compositional method; 3) any part or parts of the body can be used (subject to nature's limitations); 4) music, costume, decor, lighting, and dancing have their own separate logics and identities; 5) any dancer in the company migth be a solist; 6) any space might be danced in; 7) dancing can be about anything, but is fundamentally and primarily about human body and its movements, beginning with walking" (BANES, 1987, p. 6).

2 Rainer Vianna, filho do casal Angel e Klauss Vianna, seguiu os passos dos pais tornando-se bailarino e coreógrafo atuante na cena de dança contemporânea carioca e paulista principalmente nas décadas de 1980 e 1990.

3 Respectivamente: (1) Homenagem ao Grupo Teatro do Movimento, no II ENGRUPEDANÇA (2010); (2) Grupo Teatro do Movimento: uma proposta de pesquisa em dança, em O Percevejo Online (2010); (3) Grupo Teatro do Movimento, em Tavares e Keiserman (2013).

4 Disponível em: < http://iiengrupe.cooperacdanca.org/homenagem-ao-grupo-teatro-do-movimento/>.

5 "II Engrupedança: Diálogos e Dinâmicas" - Organizado pelo Grupo de Pesquisa Artes do Movimento, vinculado ao PPGAC/UNIRIO, com apoio da PROEX, CAPES, FAPERJ e SESC. Promoveu o encontro entre pesquisadores em Dança e áreas afins, realizado no período de 29 a 31 de outubro de 2009, na Escola de Teatro da UNIRIO.

6 O Centro de Pesquisa Corporal Arte e Educação foi fundado por Angel, Klauss Vianna e Thereza D'Aquino 
em 1975, com cursos livres na área do movimento, dança e expressão corporal; a partir de 1983, passou a se chamar Centro de Estudos do Movimento e Artes - Espaço Novo. Rebatizado de Escola Angel Vianna, em 1985, abriga também a Faculdade Angel Vianna desde 2001. 